Cesano, José Daniel, "Los usos del Derecho Comparado en la reforma penal. Reflexiones a propósito del Anteproyecto de Código Penal Argentino elaborado por la Comisión designada por Decreto 103/2017", Nuevo Foro Penal, 92, (2019).

\title{
Los usos del Derecho Comparado en la reforma penal. Reflexiones a propósito del Anteproyecto de Código Penal Argentino elaborado por la Comisión designada por Decreto 103/2017
}

The uses of Comparative Law in criminal reform. Reflections on the Draft of the Criminal Code prepared by the Commission designated by Decree 103/2017

José Daniel Cesano ${ }^{1}$

Fecha de Recepción: 03/04/2019 - Fecha de aceptación: 08/05/2019

DOI: $10.17230 /$ nfp.15.92.5

\section{Resumen}

El presente artículo tiene por objeto analizar una de las funciones del Derecho comparado. Concretamente, su propósito es indagar como, el Derecho comparado puede ser un elemento auxiliar para realizar la formulación de la política legislativa de un Estado. En este caso se reflexionará a partir de algunas instituciones reguladas por el anteproyecto de reforma del Código penal elaborado por la Comisión designada por Decreto 103/2017.

\section{Abstract}

This article aims to analyze one of the functions of Comparative Law. More specifically, its main purpose is to investigate how Comparative Law can be an auxiliary element 
to carry out the formulation of the legislative policy of a State. In this case from some institutions regulated by the preliminary draft reform of the Criminal Code prepared by the Commission designated by Decree103/2017.

\section{Palabras clave}

Derecho comparado, reforma penal, penas y medidas de seguridad.

\section{Keywords}

Comparative law, criminal reform, penalties and security measures.

\section{Sumario}

1. Necesidad de reforma; 2. Visitando el anteproyecto; 3. El uso del Derecho comparado a partir de algunas instituciones modificadas; 4. Sobre los usos del Derecho comparado en la labor de redacción del anteproyecto: Algunas reflexiones conclusivas.

5. Bibliografía.

\section{Necesidad de la reforma}

El Código penal argentino vigente fue promulgado como Ley 11.179 el 29 de octubre de 1921. Indudablemente, este texto ha sido objeto, a lo largo de sus casi cien años, de varias modificaciones parciales. Hay enmiendas que estuvieron orientadas a actualizar las técnicas de protección de determinados intereses sociales que, al tiempo de la sanción originaria, no resultaban relevantes 0 , directamente, por encarnar una problemática que, por entonces, se ignoraba no podrían haberse considerado; tal como sucede, por ejemplo, con el Título XIII, del Libro II, que incorporó los delitos contra el orden económico y financiero (Ley N²6.683) o con la Ley 26.388, que incluyó nuevos tipos delictivos que se vinculan con la denominada criminalidad informática. En otros casos las modificaciones se inscribieron en un endurecimiento del sistema de penas, que respondía a reclamos de seguridad; aspecto que puede constatarse en la ley $N^{\circ} 27.375$, que modificó el régimen de la libertad condicional, extendiendo la prohibición de este instituto en relación a un nutrido catálogo de delitos que superaba a los ya previstos por la ley 25.892, 0 en la ley 25.928, que fijó la pena máxima para el concurso material de delitos en cincuenta años. 
202 Los usos del Derecho Comparado en la reforma penal. Reflexiones a propósito del Anteproyecto de Código

Penal Argentino elaborado por la Comisión designada por Decreo - José Daniel Cesano

Con todo, y a pesar de estas reformas, podríamos convenir que, pese al paso de los años, en líneas generales, la estructura original del Código se conserva.

Esto no significa, desde luego, que muchas de las exigencias de la sociedad de riesgo ${ }^{2}$ que se traducen en la necesidad de actualizar el Código penal, no se hayan realizado. Lo que ocurre es que, desde hace también varios años, el legislador argentino pretende llevar a cabo esta tarea a través de leyes especiales o complementarias del Código penal; lo que produce un fenómeno de descodificación en esta materia ${ }^{3}$. Esto se agrava aún más, si advertimos que, algunas de estas intervenciones, ni siquiera están justificadas porque representan claros ejemplos de un verdadero Derecho penal simbólico; entendiendo por tal:

lo que Díez Ripollés ha llamado 'el reino del proceder legislativo declarativo - formal' según el cual la pretensión de la norma penal no es más que reflejar la opinión pública sobre una determinada realidad social, de manera que aquella se transforma, más que en un intento serio de atajar un problema, en una declaración formal del rechazo del mismo 4 .

Esta situación, indudablemente, se torna preocupante en la medida en

2 La paternidad de este concepto pertenece a Ulrich Beck, quien en 1986, publicó en Alemania su obra Risikogesellchaft - La sociedad del riesgo -. El punto de partida del autor es la propia noción de sociedad del riesgo. Con esta expresión Beck se refiere a un estado de desarrollo en el que las bases de la organización social ya no sólo son la administración y distribución de los recursos, sino, fundamentalmente, la distribución de los riesgos. En palabras suyas: "mientras que en la sociedad industrial la 'lógica' de la producción de riqueza domina a la lógica de la producción de riesgos, en la sociedad del riesgo se invierte esta relación" (cfr. BecK, ULRICH, La sociedad del riesgo: hacia una nueva modernidad, Ed. Paidós, Barcelona, 1998, p. 19). Para Beck los riesgos "modernos" no son del todo calculables; además, sus daños son difícilmente imputables a alguien en particular y, lo que es peor, pueden resultar irreparables. Lo trascendente de todo ello es que los nuevos peligros: "traen como consecuencia que la realidad se perciba y estructure a nivel cognitivo de acuerdo a un esquema de seguridad y riesgo" (cfr. La sociedad..., op. cit., p.22). Las implicancias de estos conceptos para el Derecho se traducen en los siguientes caracteres: a) la existencia de un cambio en el potencial de los peligros actuales en relación con los de otras épocas (la sociedad actual se caracteriza por la existencia de riesgos "artificiales", es decir, aquellos producidos por la actividad del hombre y conectados a una decisión suya, a diferencia de lo que acontecía en el pasado, cuando los riesgos provenían de la propia naturaleza); b) la complejidad organizativa de las relaciones de responsabilidad y c) la sensación de inseguridad subjetiva, independiente de los peligros reales (cfr. Ortega Maldonado, Juan Manuel, "El derecho en la sociedad de riesgo", Misión Jurídica. Revista de Derecho y Ciencias Sociales, Vol. 4, № 4, Julio - Diciembre de 2011, Universidad Colegio Mayor de Cundinamarca, pp. 78-80).

3 Sobre este aspecto, cfr. Cesano, José Daniel, La política criminal y la emergencia (Entre el simbolismo y el resurgimiento punitivo), Ed. Mediterránea, Córdoba, 2004.

4 Becerra Muñoz, José, La toma de decisiones en la política criminal. Bases para un análisis multidisciplinar, Tirant lo Blanch, Valencia, 2013, p. 75. 
que se concreta en un proceso de descodificación. Tal proceso aparece como una proyección del neopunitivismo que caracteriza a la política criminal argentina actual y se manifiesta a través de una incorporación desenfrenada de nuevas tipificaciones 0 agravaciones incoherentes de las penalidades ya existentes; desvirtuando así el correcto y ordenado funcionamiento de un conjunto - el código penal - "que, también en cada uno de sus componentes, está pensado para actuar con concertada unidad. En las leyes especiales y en las reformas de los códigos se altera siempre o se desfigura la armonía de su estructura"5.

Esta situación patológica de descodificación:

(...) ha conducido a un verdadero 'caos jurídico penal'. Esta descodificación, este legislar penalmente extra codicem, se expresa en la emisión, prolífica y ya inabarcable, de miles de figuras delictivas, muchas veces con sus propios principios generales y sus propias reglas procesales, que no integran los códigos respectivos (leyes complementarias, especiales 0 delitos y procedimientos creados por leyes no penales). Esta modalidad de legislar no respeta los principios de fundamentación técnica y axiológica que un código busca asegurar (armonía, racionalidad, centralización, congruencia, igualdad, vigencia efectiva de las disposiciones de la parte general, certeza, accesibilidad, inteligibilidad, seguridad jurídica, etc. ${ }^{6}$.

Nadie, por consiguiente, duda que el Código penal argentino está necesitado de una modificación integral, que recodifique, en forma armónica y racional, la enorme cantidad de leyes que se han venido dictando en materia penal por fuera de él y que actualice, de acuerdo a las nuevas exigencias sociales, un texto que fue pensado para otro siglo y aquel inabarcable número de leyes complementarias y especiales, que expandieron los ámbitos de punición; algunas consultando intereses merecedores de tutela penal y otras no, dotando de proporcionalidad y sistematicidad al orden jurídico penal.

De hecho, en los quince primeros años de este siglo, la República Argentina experimentó dos procesos de reforma integral de su Código Penal: el del año 2006, cuya elaboración fuera dispuesta por las Resoluciones del Ministerio de Justicia y Derechos Humanos No 303/04 y No 136/05, y el presentado, en el año 2014,

5 Pastor, Daniel R., Recodificación penal y principio de reserva de código, Ed. Ad - Hoc, Bs. As., 2005, pp. 44-45.

6 Pastor, Daniel R., "La recodificación penal en marcha. Una iniciativa ideal para la racionalización legislativa", Revista Pensar en Derecho, Coedición Eudeba y Facultad de Derecho de la UBA, Bs. As., 2012, p. 40. 
redactado por una comisión designada por Decreto del Poder Ejecutivo Nacional $N^{\circ}$ 678/2012. Ambos proyectos, sin embargo, no merecieron la aprobación del Congreso Nacional. Por eso, y ante el fracaso de aquéllos, no puede sorprender que, el actual gobierno conformase una nueva Comisión para la Reforma del Código Penal de la Nación, creada por decreto $N^{\circ} 103 / 2017$.

Desde luego que esto no significa adherir a la opción metodológica del gobierno para llevar a cabo esta decisión. Que deba reformarse integralmente nuestro Código no significa que, tal necesidad, hubiese exigido un trabajo ex novo, con otra Comisión que elaborase un documento enteramente nuevo. Sostenemos esto porque, como ya lo señalamos, existían dos anteproyectos de excelente factura, que podrían haberse reexaminado, por parte del Poder Ejecutivo, con la finalidad de unificarlos en un solo texto 0 , en todo caso, optar por uno de ellos para que, sobre la base de lo ya realizado, se pudiera consensuar la reforma del Código. Especialmente, debe señalarse como un argumento a favor de la reconsideración del último de los anteproyectos, la circunstancia de que éste estuvo redactado por una comisión cuya constitución reflejaba una amplia representación del arco político, por entonces, opositor. De hecho, uno de los miembros de aquélla es el actual vicepresidente provisional del Senado Argentino, Federico Pinedo. Por otra parte, y en el caso de ambos anteproyectos anteriores, las respectivas comisiones se caracterizaron por abrir el producto que habían elaborado a la consulta de grupos expertos, instituciones ${ }^{8}$, etcétera; aspecto que, en el caso del texto que consideramos no se realizó. Si hubo participación de diversos sectores durante la etapa de elaboración - más de 40 especialistas sobre distintos aspectos, según lo señala Carlos González Guerra, uno de los miembros de la comisión ${ }^{9}$ - mas no hubo una instancia formal que habilitase una ronda de opiniones tras la culminación del texto.

7 La Comisión estuvo integrada originariamente por Mariano Hernán Borinsky, quien actuó como Presidente; Carlos Mauricio González Guerra, quien se desempeñó como Secretario; Pablo Nicolás Turano, que actuó como Secretario Adjunto; Carlos Alberto Mahiques; Patricia Marcela Llerena; Víctor María Vélez; Pablo López Viñals; Guillermo Jorge Yacobucci; Fernando Jorge Córdoba y Patricia Susana Ziffer, y por un representante de los Ministerios de Seguridad y de Desarrollo Social.

8 En el caso del Anteproyecto designado por el Decreto 678/2012, por Resolución Rectoral № 690/2014, la Universidad Nacional de Córdoba conformó una Comisión de Especialistas en Derecho Penal y Criminología, para que dictaminasen sobre el Anteproyecto. Al respecto, cfr. Yanzı FerRelRA, Ramón Pedro (Coordinador), Estudios sobre el Anteproyecto de Reforma del Código Penal de la Nación Argentina, Universidad Nacional de Córdoba, Facultad de Derecho y Ciencias Sociales, Secretaría de Posgrado, Córdoba, 2015.

9 Al respecto, cfr. el documento intitulado "Codigo-Penal.-Rendición-de-cuentas-2017", disponible en: https://www.justicia2020.gob.ar/eje-penal/reforma-del-codigo-penal-la-nacion/. Accedido: 15/03/2018. 
El dato lo mencionamos porque creemos que, más allá que la comisión ha trabajado con ambos anteproyectos ${ }^{10}$; nos parece que es un signo de marcada inmadurez $y$, en todo caso, desmedido protagonismo, haber dejado, al menos formalmente y en su concepción de trabajos integrales, aquellos esfuerzos anteriores y, en vez de continuarlos, pretender realizar algo nuevo. Esto es sintomático de la ausencia de una verdadera política criminal, entendida como verdadera política de Estado; y de la pervivencia de prácticas objetables, en donde cada gobierno que asume intenta comenzar la tarea de cero, olvidando las iniciativas anteriores, por puras cuestiones ideológicas 0, peor aún, por especulaciones electoralistas. En tal sentido no puede perderse de vista el rol gravitante de los medios masivos de comunicación que, a partir de una información de muy baja calidad sobre el fenómeno delictivo, impacta sobre la sociedad generando una demanda de intervención pública. La auténtica novedad de este círculo vicioso que se retroalimenta - ha dicho Becerra Muñoz:

(...) es la intervención que efectivamente se produce por parte de la clase política. Esta, lejos de afrontar los diferentes asuntos intentando precisar, en primer lugar, si existe o no un auténtico problema, ha descubierto que el electorado tiene una necesidad y que su satisfacción genera beneficios electorales. Desde esta perspectiva política existe, por tanto, una necesidad de mayor seguridad y se puede responder a ella a un precio prácticamente gratuito: la publicación de normas"1".

\section{Visitando el Anteproyecto ${ }^{12}$}

El Anteproyecto consta de tres libros: Disposiciones generales; De los delitos; y De los delitos contra el orden internacional.

El libro Primero está integrado por catorce Títulos. A saber: Aplicación de la ley penal; De las consecuencias jurídicas del hecho; Condenación de ejecución Condicional; Cumplimiento en detención domiciliaria; Reparación de perjuicios; Imputabilidad; Responsabilidad de las personas jurídicas; Pautas para la determinación de las sanciones; Tentativa; Participación criminal; Reincidencia; Concurso de delitos; Extinción de acciones y penas; Del ejercicio de las acciones;

10 Vid. documento citado en nota anterior.

11 Becerra Muñoz, op. cit., p. 99.

12 Cfr. Anteproyecto. Código penal de la Nación Argentina. Anteproyecto elaborado por la "Comisión para la Reforma del Código Penal de la Nación", creada por decreto 103/2017. Ed. Eudeba, Bs. As., 2018. 
De la suspensión de proceso a prueba; y Significación de conceptos empleados en el Código.

Las mayores innovaciones en este Libro están dadas, en relación al Código vigente, por la regulación, autónoma y con particularidades, de la detención domiciliaria, actualmente regulada como prisión domiciliaria dentro del Título “De las penas", aunque con mayor especificidad en la ley de ejecución de la pena privativa de la libertad; y la inclusión de un nuevo Título destinado a la regulación de la responsabilidad penal de las personas jurídicas.

Por supuesto que aún cuando se conserven la mayoría de los otros Títulos tradicionales del Código de 1921, hay un elenco de variadas modificaciones a sus instituciones; tales como, por ejemplo, una nueva fórmula para la pena de la tentativa cuando se trate de delitos castigados con pena de prisión temporal; la previsión de una regla específica para el estado de necesidad exculpante; la regulación expresa de la capacidad de culpabilidad disminuida; una serie de incorporaciones y enmiendas en relación a las consecuencias jurídicas del delito, sobre las cuales volveremos enseguida ${ }^{13}$; entre otras reformas.

Por su parte, en el Libro Segundo se agregan - en parte en sintonía con el propósito de recodificación de la legislación penal especial, aunque también por exigencias de actualización - quince nuevos Títulos referidos a terrorismo y financiamiento del terrorismo, delitos de narcotráfico y estupefacientes, delitos fiscales, aduaneros, cambiarios, militares, delitos de tráfico y permanencia ilegal de migrantes, delitos contra la libertad y la dignidad del trabajo, delitos de tráfico de sangre, órganos y delitos genéticos, delitos contra el ambiente, contra el patrimonio arqueológico y paleontológico, delitos en el deporte, delitos informáticos y contra la propiedad intelectual.

La incorporación de los delitos internacionales, como nuevo Libro, indudablemente responde a una orientación de la política criminal actual mundial, en virtud de la cual se refleja el nuevo papel que está jugando la comunidad internacional en la construcción de la política criminal interna de los estados.

13 Por razones metodológicas desarrollamos la regulación que realiza el Anteproyecto respecto de la pena de prisión perpetua, la libertad condicional y de seguimiento socio judicial, Infra, N III. 


\section{El uso del Derecho comparado a partir de algunas instituciones modificadas}

Nuestro propósito es detenernos en ciertos aspectos de la regulación del anteproyecto; especialmente teniendo en cuenta una cuestión: la forma en que la comisión utilizó, o pudo utilizar, el Derecho extranjero14; especialmente desde la perspectiva de las funciones del Derecho comparado. Esto lo consideramos importante porque uno de los miembros de la comisión de reforma - quien, a su vez, fue uno de los coordinadores de la labor realizada -, Carlos González Guerra, señaló, como uno de los productos generados, el análisis del Derecho comparado.

¿Cómo se hizo esa tarea? Y, en especial, si se utilizó de manera adecuada el Derecho comprado, constituye el núcleo central de este trabajo.

Tomaremos como campo de indagación algunas previsiones normativas contenidas en el título II, del Libro l; esto es: De las consecuencias jurídicas del hecho. En especial, queremos focalizarnos en dos instituciones: a) la pena de prisión perpetua y su relación con la libertad condicional y b) el seguimiento socio judicial, como medida de seguridad.

¿Por qué limitamos la investigación únicamente a estos aspectos?

Lo hacemos porque creemos que es en relación a este subsistema normativo en donde se advierten los mayores desaciertos en que se incurrió al elaborar el anteproyecto. Y lo sostenemos así ya que, indudablemente, el documento que analizamos tiene innovaciones destacables; tal como sucede con la inclusión de la imputabilidad disminuida o la recodificación de leyes penales especiales. Sin embargo, el corazón de cualquier reforma integral de un Código penal debe transitar por su sistema de consecuencias jurídicas; esto es: una adecuada y razonable regulación de las penas y medidas de seguridad; cuestión que, a nuestro juicio, ha tenido, aquí, un tratamiento, por lo menos, descuidado.

Explicados los motivos de esta selección temática, debemos señalar que el anteproyecto mantiene la pena de prisión perpetua. En este sentido se apartó de las dos experiencias reformadoras anteriores que optaron por la eliminación de esta sanción; estableciendo únicamente la pena de prisión temporal y previendo como máximo posible de dicha especie, veinticinco años (en el anteproyecto de 2006) y treinta años (en el anteproyecto elaborado por la comisión designada en 2012).

14 Indudablemente, de acuerdo a los objetivos que señalamos en el texto, el trabajo comparativo que realizamos se vinculará con aquellas legislaciones extranjeras que han sido empleadas como fuente externa por el anteproyecto. Éstas, en relación a la temática que aquí tratamos, son: la española, la francesa y la alemana. 
Cabe señalar que en la larga historia legislativa del Código vigente siempre se mantuvo la pena de reclusión y prisión perpetuas. Sin embargo, los casos de perpetuidad existencial de la pena - esto es: de un encierro efectivamente de por vida - aparecían muy limitados por el instituto de la libertad condicional que permitía acceder a un egreso anticipado a prueba, a partir de los veinte años de cumplimiento de la condena. Con lo cual, salvo la hipótesis del reincidente, luego condenado por un delito conminado con prisión o reclusión perpetua, en donde el artículo 14 impedía la libertad condicional, en la mayoría de las situaciones, la pena perpetua no era tal, sino que, la posibilidad de aquel egreso permanecía como una expectativa lograble.

Los problemas comenzaron con las sucesivas modificaciones al régimen de la libertad condicional a través de las leyes 25.892 y 27.375 , que elevaron la exigencia de cumplimiento a treinta y cinco años de incorporaron, al artículo 14 del Código penal, un nutrido catálogo de delitos, muchos de los cuales están sancionados con la escala penal rígida de una pena de prisión o reclusión perpetua.

En el anteproyecto, al igual que el Código vigente, continúa existiendo la posibilidad de que un condenado a pena perpetua, a partir de los treinta y cinco años de cumplimiento, pueda solicitar la libertad condicional. En realidad, la novedad del anteproyecto en esta materia se encuentra en el artículo 14; texto que dispone:

La libertad condicional no se concederá a los reincidentes salvo que hubiesen cumplido treinta y cinco (35) años de prisión y hubiesen concurrido los demás requisitos señalados en el artículo 13. Si la reincidencia fuera múltiple el plazo ascenderá a cuarenta (40) años.

Tampoco se concederá en el caso de condenados por delitos dolosos cometidos con violencia que hubiesen conllevado para la víctima graves daños a la salud o la muerte, salvo que hubiesen transcurrido los plazos establecidos en el primer párrafo.

Se considerará que concurre uno de los casos previstos en el segundo párrafo si hubiese recaído condena por homicidio agravado, abuso sexual agravado, secuestro extorsivo o cualquier otra privación ilegal de la libertad agravada, trata de personas, tortura, desaparición forzada de personas, delitos de lesa humanidad, genocidio, delitos de guerra y terrorismo.

Tampoco se concederá en los casos de corrupción de menores, explotación de la prostitución, contrabando agravado, financiamiento del terrorismo y tráfico de estupefacientes. 
Si se compara el tratamiento del texto del anteproyecto en esta materia, con otras legislaciones extranjeras, a la luz de las funciones del Derecho comparado, debemos señalar que no se ha hecho una indagación a fondo de las posibilidades que actualmente se ofrecen.

Es que, como bien lo han señalado algunos de los miembros de la Comisión que han objetado puntualmente esta regulación ${ }^{15}$, es indiscutible que el texto proyectado se ha quedado a mitad de camino. Y decimos esto porque, por un lado, mantiene la prisión perpetua pero, por otro, no sólo conserva aquellas limitaciones previstas por el artículo 14, según las leyes 25.892 y 27.375, sino que, además, ha ampliado las posibilidades de su aplicación con una fórmula abierta, como lo es la del párrafo $2^{\circ}$, del mencionado artículo; con lo cual, los riesgos de una pena perpetua existencial esto es: literalmente de por vida -, si se sanciona este documento, serán altísimos. Es cierto que también se incluye una suerte de válvula de escape en el mismo párrafo $2^{\circ}$ del mentado artículo 14 que permitiría el acceso a la libertad condicional cuando "hubiesen transcurrido los plazos establecidos en el primer párrafo". Sin embargo, la extensa duración del tiempo de condena que se exige (treinta y cinco o cuarenta años) resultan excesivamente prolongados; con lo cual, los problemas constitucionales que plantea las penas perpetuas, aún con esa posibilidad, se mantienen indemnes.

La segunda institución que queremos puntualizar es el seguimiento socio judicial, como una medida de seguridad posterior al cumplimiento de la pena.

El seguimiento socio-judicial está previsto en el artículo 10; al disponer que:

En los casos previstos por los artículos 80, 119, 120, 121, 122, 123,124, 125, 126, 127, 128, 130 y en el Libro Tercero del presente Código o aquellos delitos que hubieran sido calificados en la sentencia como constitutivos de violencia de género, el tribunal podrá ordenar que con posterioridad al cumplimiento de la pena impuesta, se disponga un seguimiento socio judicial al que el condenado estará obligado a someterse, consistente en medidas de vigilancia y asistencia destinadas a prevenir la comisión de nuevos delitos, por el período que se deberá establecer en la sentencia y el que no podrá superar de diez (10) años.

Las medidas de vigilancia concretas, que pueden aplicarse individualmente 0 varias de ellas en conjunto son las siguientes:

15 Cfr., por ejemplo, la disidencia de Vétez, Víctor María, en Anteproyecto. Código penal de la Nación Argentina, op. cit., p. 257 y siguientes. 
210 Los usos del Derecho Comparado en la reforma penal. Reflexiones a propósito del Anteproyecto de Código

Penal Argentino elaborado por la Comisión designada por Decreo - José Daniel Cesano

$\left.1^{\circ}\right)$ La obligación de estar siempre localizable mediante dispositivos electrónicos que permitan su seguimiento permanente. $2^{\circ}$ ) La obligación de presentarse periódicamente en el lugar que el órgano competente establezca. $3^{\circ}$ ) La obligación de comunicar inmediatamente, en el plazo máximo y por el medio que el órgano competente señale a tal efecto, cada cambio del lugar de residencia o del lugar o puesto de trabajo. $4^{\circ}$ ) La obligación de participar en programas formativos, laborales, culturales, de educación sexual u otros similares. $5^{\circ}$ ) La obligación de seguir tratamiento médico o psicológico externo, o de someterse a un control médico periódico. $6^{\circ}$ ) La prohibición de ausentarse del lugar donde resida 0 de un determinado territorio sin autorización del órgano competente. $7^{\circ}$ ) La prohibición de aproximarse a la víctima, 0 a aquellos de sus familiares $u$ otras personas que determine el órgano competente. $8^{\circ}$ ) La prohibición de comunicarse con la víctima, o con aquellos de sus familiares u otras personas que determine el órgano competente. $9^{\circ}$ ) La prohibición de acudir a determinados lugares o establecimientos. 10) La prohibición de residir en determinados lugares o establecimientos. 11) La prohibición de desempeñar determinadas actividades que puedan ofrecerle o facilitarle la ocasión para cometer hechos delictivos de similar naturaleza.

El artículo 11, por su parte, prevé el carácter revisable de esta medida, así como algunas generalidades respecto a este proceso de revisión. La norma en cuestión expresa:

El órgano competente podrá revisar en todo momento la idoneidad de la medida de seguimiento socio judicial o el logro de su finalidad.

La revisión será obligatoria, por primera vez, a más tardar, en un (1) año desde su disposición, y deberá ser reiterada cada seis (6) meses, debiendo ser dejada sin efecto en caso que existieran indicios serios de que el condenado se encontrase en condiciones de ajustar su conducta a la legalidad.

Para ello, deberán valorarse los informes emitidos por los profesionales que asistiesen a la persona sometida a las medidas, las evaluaciones del servicio penitenciario acerca de la situación y la evolución del condenado, su grado de rehabilitación y el pronóstico de reiteración delictiva.

El órgano judicial competente resolverá motivadamente a la vista de la propuesta o los informes a los que respectivamente se refiere el tercer 
párrafo, una vez oída a la propia persona sometida a la medida, así como al Ministerio Público Fiscal y las demás partes. En caso de solicitarlo, podrá oírse a la víctima, aunque no hubiera sido parte en el proceso.

¿Hizo la Comisión, al menos en estas materias, un buen uso de las experiencias extranjeras?

La impresión es que no.

Para llegar a esta conclusión es necesario realizar un recorrido que parta, precisamente, de las características que tiene una de las funciones particulares que se le asigna al Derecho comparado ${ }^{16}$; concretamente como elemento auxiliar para realizar la formulación de la política legislativa de un Estado $0^{17}$.

En efecto, la soberanía estatal, a la hora de crear el derecho nacional, no es cerrada ni absoluta, sino que se muestra abierta y relativa. "Las normas nacionales se crean (...), con mucha frecuencia, bajo la influencia, el trasplante, (...) la copia 0 la imitación a la tradición de materiales jurídicos extranjeros y comparados" ${ }^{\prime 18}$. Cuando se asume la necesidad de regular sobre determinada cuestión (trátese de introducir una institución novedosa o de modificar una ya existente) se acostumbra a tomar, como punto de partida, lo que previamente han establecido los ordenamientos jurídicos extranjeros; en especial, primeramente, respecto de los Estados pertenecientes a la misma familia jurídica y previa evaluación del prestigio intelectual de los productos normativos ${ }^{19}$; para, más tarde, extender el relevamiento a los demás sistemas jurídicos que comparten similares valores y una concepción general sobre la forma de entender el rol que el derecho desempeña en una sociedad ${ }^{20}$. Por ello, en la actualidad, un legislador responsable, no puede prescindir "del trabajo comparativo previo (...), pues sólo mediante el conocimiento completo de lo que tiene vigor en el extranjero, se obtiene el 'acopio de provisiones' (...) disponible para una determinada tarea social"21.

Una buena muestra de esta actitud está representada por los trabajos previos de Derecho comparado que precedieron a la $2^{\mathrm{a}}$ Ley para la reforma del Derecho Penal Alemán, del 4 de julio de 1969, que modificó integralmente la Parte General del Derecho Penal material. En efecto, la preparación de esta reforma comenzó en 1953, bajo la iniciativa del entonces Ministro Federal de Justicia, Thomas Dehler. Él dio principio a esta gran empresa pidiendo informes a los principales penalistas

20 Serra, Francisco, "La actualidad del derecho comparado", en Pedro Aullón Haro (Editor), Metodologías comparatistas y Literatura comparada, Clásicos Dykinson, Madrid, 2012, pp. 185-186.

21 Jescheck, Hans - Heinilch, Tratado de Derecho Penal. Parte general, 4a Edición, Ed. Comares, Granada, 1993, p.38. 
212 Los usos del Derecho Comparado en la reforma penal. Reflexiones a propósito del Anteproyecto de Código

Penal Argentino elaborado por la Comisión designada por Decreo - José Daniel Cesano

alemanes acerca de los problemas fundamentales de la reforma, y encargado al Max-Planck-Institut für ausländisches und internationales Strafrecht de Freiburg "la elaboración de amplios informes comparativos de la parte general y de la parte especial del Derecho penal"22.

Ahora bien, el estudio de experiencias foráneas no implica la simple importación de soluciones ni la imposición de sus figuras, "si no el estudio de la idoneidad de instituciones extranjeras a las necesidades 0 problemas nacionales" ${ }^{\prime 23}$. Por eso, acertadamente, se ha señalado que un estudio comparativo no pretende copiar soluciones de propuestas extranjeras, sino adquirir ideas que puedan traer una solución de instituciones similares, susceptibles de ser trasplantadas y adaptadas a las condiciones locales ${ }^{24}$.

De lo expresado hasta aquí se puede inferir que el uso del Derecho comparado, en estos casos, está íntimamente vinculado con el fenómeno de la circulación de los modelos normativos y, en consecuencia, con las delicadas cuestiones que dicho concepto supone.

La circulación se produce en diferentes escalas; pudiendo concretarse en la inspiración que, respecto de un determinado sistema receptor, produce una institución jurídica extranjera en particular ${ }^{25}$. Sin embargo, como lo plantea Dubois, esta situación genera innumerables preguntas; las que traducen dificultades diversas. En efecto:

¿Cuáles son los instrumentos por los cuales se lleva a cabo esta circulación? ¿Cuáles son los factores que pueden explicarlas? ¿Cómo se imponen ciertos modelos normativos a los demás? ¿Cómo pueden participar los intercambios legales para mejorar o instrumentalizar la ley? ¿Cómo y por qué un Estado elige importar un nuevo modelo? ¿Cómo se adapta ese modelo? ${ }^{26}$.

22 Beristain, Antonio, "La reforma del Código penal alemán", Anuario de Derecho penal y Ciencias penales, Número 2, Madrid, 1969, p. 372.

23 Mancera Cota, Adrián, "Consideraciones durante el proceso comparativo", Boletín Mexicano de Derecho Comparado, №121, Enero de 2008, p. 222.

24 En este sentido se pronuncia Tallon, DenIS, "Comparative Law: Expanding Horizons", The Journal of the Society of Public Teachers of Law, vol. X, 1968-1969, London pp. 265-272.

25 Mure, AurélIE, "La circulation des modèles normatifs: la class action à la française", en La circulation..., op. cit., p. 36.

26 DuBoıs LÉA, "Propos introductifs sur la circulation des modèles normatifs: tentative de définitions", en La circulation des modèles normatifs, op. cit., p. 31. 
Son algunos de los interrogantes que un legislador atento debiera formularse y responder, antes de hacer su propuesta normativa, inspirada en preceptos extranjeros. A lo recién expresado debe añadirse otro recaudo no menor, agudamente señalado por Somma:

No hace falta decir que la imitación de la ley extranjera, si no toma en cuenta el contexto en el que sus principios y reglas han madurado, o si lo hace de manera superficial, está destinada a resultar en una falla 0 al menos está condenada a producir resultados muy distantes de aquellos prefigurados por los imitadores ${ }^{27}$.

Focalicemos ahora nuestra atención en la forma en que el anteproyecto reguló las dos instituciones que hemos analizado.

¿Qué podemos extraer de estas previsiones?

Varias cuestiones:

La primera es que hay una marcada necesidad de endurecimiento del sistema penal e, incluso, de aumentar los controles respecto de las personas que han delinquido y cumplido su pena, a través de la imposición de esta nueva medida de seguimiento socio judicial. Es más: en relación a este endurecimiento punitivo hay una curiosa declaración retórica, transformada en artículo, que proclama la obviedad de que "Las penas serán de cumplimiento efectivo, salvo en los supuestos en los que expresamente este Código disponga lo contrario" (art. 5, $3^{\circ}$ párrafo). Esto siempre fue así: los jueces no pueden imponer sanciones que no sean efectivas; a menos que resulte aplicable la condena de ejecución condicional; prevista tanto en el Código actual como en el documento que analizamos. Creemos que este curioso texto proyectado es una clara muestra de una previsión meramente simbólica, que se ha colocado como slogan para responder a otro slogan, en este caso proveniente de los mass media, y que se queja, permanentemente, de que la judicatura puede disponer a su antojo cuándo una pena es efectiva o cuándo una pena puede no serlo o que puede acortar la ejecución de éstas caprichosamente. Los juristas sabemos que esto no es cierto y, sin embargo, para tranquilizar a la opinión pública, la comisión entendió necesario incluir semejante cláusula; descalificable, desde el punto de vista de la técnica legislativa, por ser sobreabundante, y desde las motivaciones, por su tinte demagógico.

En segundo lugar, y como ya lo anticipamos, la comisión optó por la continuidad de una vieja tradición legislativa argentina que consideraba admisible la pena de

27 Somma, Introduzione..., op. cit., p. 54. 
214 Los usos del Derecho Comparado en la reforma penal. Reflexiones a propósito del Anteproyecto de Código

Penal Argentino elaborado por la Comisión designada por Decreo - José DANIEL Cesano

prisión perpetua. El problema es que, aquella tradición, en su puridad originaria, se caracterizaba, en todo caso, por zafar de la tensión que provoca una perpetuidad real, a través de una regulación bastante razonable de la libertad condicional. Y en este sentido, las reformas posteriores a este instituto, han vaciado de razonabilidad al sistema; con el catálogo de delitos excluidos por el artículo 14 y, ahora agravado, además, con la cláusula abierta que propone el mismo artículo, según la redacción del anteproyecto.

Por eso, decíamos, que aquí la comisión se ha quedado a mitad de camino, intentando, con la regla de la disposición final del párrafo $2^{\circ}$, del mentado artículo 14, entreabrir una rendija - es tan mínima que ni siquiera podemos decir que abrió una puerta - frente a esta grave situación. En este aspecto, consideramos, que la comisión no hizo un buen trabajo con el Derecho comparado. Y sostenemos esto porque existen instituciones en el Derecho extranjero que, sin renunciar a las penas perpetuas, prevén mecanismos de revisión judicial. Y este es un aspecto en donde un uso adecuado del Derecho comparado podría haber aportado alguna solución más racional a la cuestión. Nos referimos, concretamente, a la suspensión de la cadena perpetua, prevista por la legislación alemana ${ }^{28}$.

Aquí, creemos, que debemos detenernos, un instante, para precisar varias cosas.

Por una parte, personalmente, estimamos que la prisión perpetua presenta graves problemas de constitucionalidad. Decimos esto por dos razones. Por una parte ya que, el principio de readaptación social que los pactos internacionales constitucionalizados (art. 75, inc. 22, Constitución Argentina) han establecido como uno de los objetivos que persigue la ejecución penitenciaria (art. 5.6, Convención Americana de Derechos Humanos y art. 10.3, Pacto Internacional de Derechos Civiles y Políticos), contrarían abiertamente este principio en la medida en que una conminación con tal especie de pena representa una presunción iuris et de iure de ineficacia del tratamiento; lo que constitucionalmente es inadmisible y empíricamente indemostrable. Desde otra perspectiva, porque una pena existencialmente perpetua supone una forma de aniquilación civil y social; ambas inhumanas por su contenido inocuizante ${ }^{29}$.

28 En España se prevé, a partir de la Ley Orgánica N 1/2015, que modificó el Código Penal, la pena de prisión permanente revisable. Como veremos en el texto, el sistema español estableció (art. 92) requisitos temporales mucho más exigentes que otras legislaciones europeas, para que un condenado, castigado con esta especie de pena, pueda acceder a su revisión.

29 Cfr. Cesano, José Daniel, "¿Penas privativas de la libertad efectivamente perpetuas? (A propósito de un fallo del Superior Tribunal de Justicia de Rio Negro)", Revista de Derecho penal y Procesal penal, diciembre de 2004, № 4, Ed. LexisNexis, Bs. As., p.775. 
Por tales motivos, en nuestra opinión, lo correcto hubiese sido establecer un máximo legal para esta especie de pena; de manera tal que siempre fuese una pena temporal.

Ahora bien, si de acuerdo a nuestra tradición legislativa la perpetuidad se admite - y de hecho se la viene considerando admisible, incluso desde una perspectiva jurisprudencial-; también hubiese sido conveniente, continuando con aquella tradición casi centenaria, prever remedios eficaces que hagan posible neutralizar, en alguna buena medida, las tensiones constitucionales que provoca aquella perpetuidad. Una de estas instituciones es la libertad condicional, razonablemente regulada; tal como la establecía el Código de 1921 o como lo hacen otras legislaciones extranjeras más modernas.

En efecto habiendo sistemas legislativos que han conservado la pena de prisión perpetua, la comisión no introdujo la solución que aquellos mismos modelos poseen para morigerar sus problemas de constitucionalidad.

En el Derecho continental europeo, para continuar en nuestra tradición jurídica, el Código penal alemán prevé una institución que, estimamos, da una respuesta racional a este problema, sin renunciar a la pena de prisión perpetua. Nos referimos, puntualmente, a la suspensión de la pena. Brevemente nos detendremos en la regulación del instituto por parte de esta legislación.

El StGB, en su parágrafo 38, párrafo $1^{\circ}$, establece el principio general de que la pena privativa de libertad es temporal, salvo que la ley imponga cadena perpetua. De esta manera, la pena privativa de libertad se configura "como una excepción a la pena de prisión ordinaria, estableciéndola el legislador de manera indefinida sólo en supuestos extraordinarios" ${ }^{\prime \prime}$.

Por otra parte, en este sistema, la cadena perpetua no se prevé siempre como sanción obligatoria, sino que, en algunos casos, se permite al juzgador su imposición facultativa; contemplándose de forma alternativa a una pena de prisión temporal ${ }^{31}$.

Esta regulación - señala Roig Torres - ha sido avalada por el Tribunal Constitucional, "que justificó su aplicación preceptiva en el delito de asesinato"32.

Hasta el año 2002, el Código penal alemán preveía la cadena perpetua de forma automática sólo en dos tipos de delito: el asesinato -equiparable a nuestros

30 Roig Torres, MargaRita, La cadena perpetua en el Derecho alemán y británico. La prisión permanente revisable, Ed. lustel, Madrid, 2016, p. 29.

31 Ibídem p. 29.

32 Ibídem p. 29, nota 6; en donde se detalla las referencias del fallo, en estos términos: BVerfGE 45 , $187 ; 62$. 
homicidios calificados - y el genocidio. Actualmente esta situación se mantiene respecto de aquellas figuras, pero se ha ampliado el catálogo de delitos a los que se asocia, como pena ineludible, la cadena perpetua, a raíz de los convenios internacionales que regulan los delitos humanitarios; originando infracciones que están reguladas por una ley penal especial. Dicha ley impone cadena perpetua para dos categorías de delitos: los crímenes de lesa humanidad y los crímenes contra las leyes de la guerra. Junto a estos cuatro casos de delitos castigados con pena privativa de la libertad perpetua, la legislación alemana también prevé otras figuras en donde hay una aplicación facultativa; por cuanto el legislador estableció una conminación alternativa con pena temporal; quedando la selección de la pena en mano de los jueces. Así, en la Ley de Introducción del Código Penal Internacional hay algunas figuras que admiten la construcción de una sanción que incluye una alternativa entre la cadena perpetua y, como sanción opcional, una pena de prisión de al menos cinco años; como sucede con algunas conductas típicas (V.gr. la sumisión a condiciones de vida que pretendan destruir a la población o causar lesiones graves a prisioneros). Asimismo, esta posibilidad está permitida en diversas infracciones delictuales previstas en el Código; cual sucede con: homicidio, alta traición, abuso sexual a menor seguido de muerte, coacción sexual y violación seguida de muerte y robo seguido de muerte.

Ahora bien, lo que caracteriza a este sistema es, justamente, la posibilidad de suspensión de la pena; aun tratándose de una cadena perpetua. Esta situación está prevista en el parágrafo 57 a) del Código vigente, norma que establece:

(1) El tribunal suspende la ejecución del resto de la pena privativa de la libertad perpetua para concederla libertad condicional cuando:

1. se hayan cumplido quince años de la pena

2. la especial gravedad de la culpa del condenado no imponga el ulterior cumplimiento; $y$,

3. existen los presupuestos del $\S 57$ inciso 1 frase 1 numeral 2 y 3.

$(\ldots)$

(3) La duración del período de libertad condicional es de cinco años. (...)

(4) El tribunal puede fijar plazos máximos de dos años, antes de cuyo vencimiento es inadmisible que el condenado presente una petición en el sentido de suspender el resto de la pena. 
Las remisiones efectuadas en el número 3) al parágrafo 57 , inciso 1), Frase 1 , numerales 2 y 3 , implican la exigencia de dos requisitos adicionales; a saber: a) la suspensión demanda, además, la particular consideración al interés de seguridad de la comunidad; y b) el condenado debe prestar su consentimiento para la aplicación del instituto.

Como hemos mencionado ya ${ }^{33}$, el Código penal español, a partir de la reforma operada en el año 2015, introdujo el instituto de la prisión permanente revisable en el actual artículo 92. En relación a la situación española, previamente, debe recordarse que, antes de esta ley, España había abolido la pena de prisión perpetua; estableciendo que la pena de prisión siempre debía ser temporal y no superior a los 20 años (artículo 36). Sin embargo, en el texto vigente se volvió a incluir la pena perpetua; estableciéndose esta nueva institución como un mecanismo que trata de atemperar los problemas constitucionales de la perpetuidad. La doctrina española sostiene que esta enmienda se inspira en la legislación alemana; aunque advierte importantes diferencias, que la alejan de aquel modelo y la tornan altamente cuestionable. En tal sentido, lo primero que se advierte es el tiempo mínimo de cumplimiento exigido; 15 años en el caso alemán y 25 años en el español. Pero, además:

en el Código penal alemán ese [15 años] es un término único, sin que se recoja un tiempo mayor para ningún supuesto, como sucede con el artículo 78 bis CP [español], donde se contemplan períodos de hasta 35 años en ciertos casos de concurrencia de delitos ${ }^{34}$.

Esta diferencia sustancial que existe en orden al período mínimo de cumplimiento es, justamente, lo que en el sistema español ha llevado a la doctrina a cuestionar la adecuación de esta pena al texto constitucional y, en particular, al principio de resocialización del artículo 25. 2 de la Constitución de aquel país ${ }^{35}$. Recientemente, y a sólo título ilustrativo, Sergio Cámara Arroyo y Daniel Fernández Bermejo han concluido en relación a esta pena expresando que:

La prisión permanente revisable es una pena incierta. Se trata de una verdadera sentencia indeterminada. Se trata de una pena grave, de naturaleza aflictiva y carácter simbólico, pues priman en ella la finalidad preventivo general (positiva y negativa) clásica del Derecho penal. En este sentido, puede decirse sin empacho alguno que la prisión permanente

33 Vid. Nota $n^{\circ} 28$.

34 Rolg Torres, La cadena perpetua..., op. cit., p. 38.

35 Ibídem p. 41. 
218 Los usos del Derecho Comparado en la reforma penal. Reflexiones a propósito del Anteproyecto de Código

Penal Argentino elaborado por la Comisión designada por Decreo - José Daniel Cesano

revisable supone en nuestro ordenamiento penal el reverso del art. 25.2 CE puesto que invierte el mandato de orientación preventivo - especial dirigido a nuestro legislador. La pena de prisión permanente revisable es, además, tiránica debido a su imperativa imposición en todos los supuestos en los que se recoge sin mayores alternativas. Es, una pena imposible de individualizar. Aunque se haya definido como una pena autónoma, la naturaleza jurídica de la prisión permanente revisable flirtea con la medida de seguridad, toda vez que hace depender la liberación del penado de un pronóstico de peligrosidad 36 .

Y hemos mencionado esta regulación porque, aunque más gravosa que la alemana, resulta indudablemente mucho menos dura que la regulada en el anteproyecto analizado; documento que, en otras materias, ha abrevado en la legislación española como fuente.

Volviendo a la regulación del anteproyecto es evidente que éste ha omitido la consideración del instituto, tal como lo regula la legislación penal alemana. Es más: ni siquiera se aproxima al modelo, mucho más severo, que representa el Código español - también objetable - ya que, en éste, como regla, la revisión procede a los 25 años; en tanto que en el texto nacional este plazo se extiende a 35040 años. Es indudable que semejantes plazos de cumplimiento como los establecidos en la disposición que comentamos no sólo obstaculiza el desarrollo de la reinserción social del penado - garantida por los artículos 5.6 de la Convención Americana de Derechos Humanos y 10.3 del Pacto Internacional de Derechos Civiles y Políticos, ambos con jerarquía constitucional (art. 75, inciso 22, C.N.) - sino que se opone frontalmente a él. Es que, como ha dicho la doctrina española con un texto más indulgente - aunque por lo ya expresado también cuestionable -:

(...) sólo quien carezca de una mínima capacidad de empatía o no haya tenido jamás contacto alguno con el mundo penitenciario puede afirmar seriamente que el internado en una cárcel durante un período tan prolongado con el previsto como mínimo antes de revisar la pena de prisión permanente, no está abocado a convertirse en un serio obstáculo para la reincorporación del penado, ya rehabilitado, a la vida en libertad, y hasta cabría afirmar, para su misma supervivencia personal ${ }^{37}$.

36 Cámara Arroyo, Sergio - Fernández Bermejo, Daniel, La prisión permanente revisable: el ocaso del humanismo penal penitenciario, Thomson Reuters - Aranzadi, Pamplona, 2016, p. 242.

37 Saéz Rodríguez, C., "Comentarios acerca del sistema de penas en la proyectada reforma del Código Penal español", InDret. Revista para el análisis del Derecho, Barcelona, № 2, 2013, p. 11. 
Creemos que la comisión hubiese sacado un buen provecho de los usos del Derecho comparado si hubiera adoptado el modelo, mucho más racional, que ofrece la ya aludida codificación alemana. Es que, las ventajas del instituto de la suspensión de la pena son infinitamente superiores al del texto proyectado. Como lo ha señalado el propio Tribunal Constitucional alemán en su sentencia del 24 de abril de 1986:

Contra lo dispuesto en el parágrafo 57 a StGB no cabe alegación de inconstitucionalidad alguna. Con su introducción, el legislador ha cumplido con el requisito constitucional de que un condenado a cadena perpetua tenga la posibilidad concreta, realizable, de recuperar su libertad en un momento posterior... La norma supone una protección de la dignidad humana. Se infringiría el núcleo de la misma si el condenado a pesar del desarrollo de su personalidad tuviera que renunciar a toda esperanza de libertad y por lo tanto se supiera condenado a morir bajo custodia; y esto rige igual para personas responsables de delitos cuya culpabilidad sea especialmente grave... El legislador recoge las condiciones en que se suspenderá la ejecución de la cadena perpetua, otorgando al preso la libertad condicional, dentro del marco establecido por la Ley Fundamental ${ }^{38}$.

Analicemos ahora la medida de seguridad de seguimiento socio judicial. Se trata de una medida complementaria a la pena de prisión y cuya ejecución comienza con el agotamiento de aquélla. En este caso, pareciera que esta sanción se ha inspirado en la legislación penal francesa ${ }^{39}$.

¿Cómo se ha regulado en Francia dicha institución?

El Código penal francés establece que para ciertos delitos y crímenes- primero sólo se refería a agresiones sexuales graves y luego lo extendió a otras figuras, tales como asesinato, homicidio, tortura 0 actos de barbarie - el juez puede ordenar el encarcelamiento y una medida de supervisión que se aplicará después de la privación de libertad ${ }^{40}$. Se trata de una auténtica medida de seguridad ${ }^{41}$, denominada suivi socio - judiciere - esto es seguimiento socio judicial -, que se encuentra definida en

38 Rolg TorRes, La cadena perpetua..., op. cit., p. 53.

39 Así opina Cuellar, Gustavo Gabriel, "Anteproyecto de Código Penal 2018. ¿Claves del nuevo código penal de argentina?", p. 5. Disponible en http://www.pensamientopenal.com.ar/system/ files/2018/07/doctrina46788.pdfp. Accedido23/03/2019. Al respecto el autor señala: "Se incorpora el seguimiento socio-judicial como una medida de seguridad posterior al cumplimiento de la pena, siguiendo el modelo del Código Penal de Francia".

40 Pradel, Jean, Droit Pénal comparé, 4e édition, Dalloz, Paris, 2016, p. 749.

41 Pradel, Jean, Droit..., op. cit., p. 749. 
el artículo 131-36-1 del Código citado.

La medida implica, para la persona condenada, la obligación de someterse, bajo la supervisión del juez de ejecución y por un período determinado por el tribunal de sentencia, a diversas medidas de supervisión y asistencia, para prevenir la reincidencia.

La duración del seguimiento socio judicial no puede exceder de diez años, en caso de condena por delito, o veinte años, en caso de condena por crimen.

La medida comienza a cumplirse desde el día que finaliza la privación de libertad a título de pena ${ }^{42}$.

El seguimiento socio judicial se dispone siempre que tras una pericia médica se constate la persistencia de la peligrosidad y la necesidad de la medida ${ }^{43}$, en función de los fines preventivos de comisión de un futuro delito; y en tanto resulten insuficientes otras alternativas, tales como la inscripción en los ficheros judiciales nacionales automatizados de autores de infracciones sexuales 0 violentas ${ }^{44}$.

La medida supone no sólo someter al sujeto que ha cumplido con la pena privativa de libertad a la continuidad de una vigilancia electrónica sino que, también, en virtud de la remisión realizada por el artículo 706-53-19 del Código Procesal Penal, a los artículos 132 - 44 y 132 - 45 del Código Penal, podrán imponérsele todas 0 algunas de las medidas de supervisión y asistencia allí mencionadas; entre las cuales destacan: responder a las citaciones del juez de sentencia o del trabajador social designado para la supervisión del caso; recibir las visitas del trabajador social y comunicarle la información o documentos que puedan permitirle controlar sus medios de existencia y el cumplimiento de sus obligaciones; informar al trabajador social de los cambios laborales, de residencia o de cualquier viaje que dure más de quince días, dando cuenta de su regreso; requerir autorización al juez para cualquier viaje al extranjero; obtener una actividad profesional o continuar su educación 0 formación profesional; establecer residencia en un lugar determinado; someterse a

42 Dispone, en este sentido, el artículo 131- 36- 5 del Código Penal: "Lorsque le suivi socio-judiciaire accompagne une peine privative de liberté sans sursis, il s'applique, pour la durée fixée par la décision de condamnation, à compter du jour où la privation de liberté a pris fin".

43 Al respecto señala Martínez Mora, Gema, Alternativas jurídicas al tratamiento penal de la delincuencia habitual, JB Bosch Editor, Barcelona, 2015, p. 73-74: "Una Comisión pluridisciplinar de medidas de seguridad evaluará la peligrosidad sobre la base de un examen pericial médico realizado por dos expertos que han de observar al condenado durante se emplazamiento en un servicio especializado por un tiempo no inferior seis semanas".

44 Requejo Rodríguez, Paloma, "Peligrosidad criminal y Constitución", InDret. Revista para el análisis del Derecho, Barcelona, Julio de 2008, pp. 9-10. 
un examen médico, tratamiento 0 atención, incluso bajo hospitalización ${ }^{45}$;justificar que contribuye a los gastos familiares; reparar total o parcialmente, dependiendo de su situación económica, el daño causado por el delito; justificar que, de acuerdo con sus poderes contributivos, paga las sumas adeudadas al Tesoro Público; abstenerse de conducir ciertos vehículos; no participar en la actividad con motivo de cuyo ejercicio cometió el delito; no ejercer una actividad que implique un contacto habitual con menores; abstenerse de concurrir a determinados lugares especialmente designados; no participar en apuestas; no relacionarse con otros sujetos condenados, en particular con los autores o cómplices de la ofensa en la que participó; abstenerse de entablar relaciones con ciertas personas, incluida la víctima, o ciertas categorías de personas, y en particular los menores; no tener ni portar armar; y, en el caso de un delito cometido contra su cónyuge, su pareja 0 sus hijos o los hijos de su cónyuge abstenerse de concurrir al lugar de residencia de aquéllos; debiendo, además, recibir, de ser necesario, atención médica, social 0 psicológica especializada.

Retornemos, nuevamente, al artículo 10 del proyecto. De su lectura es posible advertir una diferencia sustancial con el texto que le habría servido de modelo: la necesidad de un dictamen pericial que justifique la medida; en función de la probabilidad de peligrosidad en el autor, que exige la legislación francesa y que, el anteproyecto sólo considera necesario a los efectos de la revisión de la medida, desde la perspectiva de su duración.

Igualmente debemos destacar que, tal cual sucediera con el artículo 14 ya analizado, dentro de la comisión, tres integrantes se opusieron a la inclusión de esta medida ${ }^{46}$.

45 Según el artículo 132 - 45 del Código Penal, estas medidas pueden consistir en el requerimiento terapéutico previsto en los artículos L. 3413-1 a L. 3413-4 del Código de Salud Pública, cuando la persona condenada está consumiendo drogas o bebidas alcohólicas en forma habitual o excesiva. En tales el juez de ejecución enviará una copia de la decisión que ordena estas medidas al médico 0 psicólogo que debe seguir a la persona condenada.

Así, en su disidencia conjunta, Fernando Córdoba y Patricla Ziffer señalaron la inconveniencia de esta medida sobre la base de las dificultades prácticas para su control. Por su parte, Patricia Llerena se pronunció en contra de su previsión argumentando que las medidas impuestas luego del agotamiento de la pena, no se basan en un derecho penal de acto, sino en un puro derecho penal de autor, lo que tensiona las bases constitucionales que rigen el ius puniendi del Estado (cfr. Anteproyecto, op. cit., p. 170 y $245 / 246$, respectivamente). 
222 Los usos del Derecho Comparado en la reforma penal. Reflexiones a propósito del Anteproyecto de Código

Penal Argentino elaborado por la Comisión designada por Decreo - José DANIEL Cesano

\section{Sobre los usos del Derecho comparado en la labor de redacción del anteproyecto: algunas reflexiones conclusivas}

El saldo que nos ha dejado el anteproyecto con respecto a los usos que se hicieron, en los trabajos preparatorios, con relación al Derecho comparado deja un sabor un poco amargo.

El empleo del Derecho comparado, como elemento auxiliar para coadyuvar a la realización de un producto legislativo del Estado, debe estar rodeado de diversos resguardos; si es que se quiere arribar a buen puerto. Aquí mencionaremos dos: a) por una parte, un esfuerzo serio tendente a detectar cierta similitud entre las tradiciones legislativas de los textos extranjeros que se utilizan como fuente y b) por otro, un estudio de las orientaciones político criminales a las que responde la institución que pretende trasplantarse; de manera tal de evaluar la mayor o menor proximidad 0 alejamiento que existe, al momento de proyectar la reforma, entre aquélla y la orientación presente en la legislación que se intenta modificar. Brevemente nos detendremos en ambos aspectos.

En primer lugar, la necesidad de verificar la proximidad entre las tradiciones jurídicas que se pretenden imitar.

Por de pronto no es suficiente con prestar atención a un solo formante; en este caso, la norma jurídica que se quiere trasplantar. Este conocimiento, si bien necesario, no es suficiente. Por el contrario, aquella información debe necesariamente completarse incluyendo, además, "el sistema interno en su origen, en su evolución, en sus principios fundamentales, en sus fuentes, en sus procedimientos de aplicación, en su espíritu y en su contexto general de valores" ${ }^{\prime 4}$.

Al respecto, no se realiza un trabajo satisfactorio, desde la perspectiva del empleo de esta función del comparatismo cuando, en el mismo "lienzo" del texto normativo que se proyecta, se yuxtaponen propensiones extranjeras sin su contexto; lo que se explica porque, en un caso, no es posible determinar la tradición a la cual responden 0, aún cuando sea posible identificarlas, esta acumulación, cuando es irreflexiva o descuidada, termina por privarlas "de cualquier significado contextual"48.

47 Ancel, Marc, Utilità e metodi del diritto comparato. Elementi d'introduzione generale allo studio comparato dei diritti, Edizioni Scientifiche Italiane, Napoli, 2000, p. 96.

48 Samuel, Geoffrey, "All that heaven allows: are transnational codes a 'scientific truth' or are they just a form of elegant 'pastiche'?", Methods of Comparative Law, Edited by Pier Giuseppe Monateri, Research Handbooks in Comparative Law, Series Editors: Francesco Parisi and Tom Ginsburg, Published by Edward Elgar Publishing Limited, Cheltenham, UK - Northampton, M.A., USA, pp. 181182. 
Prestar atención a la tradición a la que pertenece la norma de importación es una cuestión central y requiere de diversas destrezas. Ante todo, se trata de una tarea que exige una metodología interdisciplinaria ${ }^{49}$; que no puede ser insensible a las aproximaciones de la historia jurídica.

Volvamos la atención un instante en la regulación que, de la libertad condicional para las penas perpetuas, realizara el Código penal de 1921. Fue este Código el que introdujo, en nuestro sistema jurídico, desde aquel entonces, tal institución; en reemplazo de la gracia, que establecía el Código anterior (1886). Los antecedentes inmediatos del Código de 1921 se encuentran en los proyectos de 1891 y de 1906. El proyecto de 1906, justamente, admitió la libertad condicional en relación a las penas privativas de la libertad perpetua; extremo que no admitía el proyecto de 1891. Por su parte, durante el trámite parlamentario del Código de 1921, en la revisión del Senado, se trató de limitar nuevamente la institución para estas situaciones (pena perpetua) lo que fue rechazado por la Cámara de diputados, expresando, al respecto, los miembros de la Comisión:

Pocas legislaciones niegan la libertad condicional a los condenados a perpetuidad (...), y las que la conceden señalan un plazo mínimo de encarcelamiento que va de cinco años (...), a diez (...), doce (...), quince (...), y veinte (...). El artículo 13 del proyecto en revisión, exige, para la concesión del beneficio, el cumplimiento de veinte años de condena, lo que no constituye, por cierto, exceso de benignidad. No es conveniente suprimir el beneficio [de la libertad condicional para las penas perpetuas], sobre todo si se considera que la libertad es revocable y que el liberado puede ser sometido, durante cinco años, al cuidado de un patronato. La libertad condicional es un estímulo de buena conducta, un germen de enmienda, una prima ofrecida al detenido arrepentido, y no conviene eliminar este poderoso resorte, que influye eficazmente en la conducta del

49 Samuel, Geoffrey, An Introduction to Comparative Law. Theory and Method, Oxford and Porland, Oregon, 2014, edición Kindle, posición 676, ha señalado que esta concepción epistemológica tiene una larga tradición en los estudios comparativos. Según el autor: "Esta necesidad de un enfoque interdisciplinario del derecho comparado es uno de los otros puntos destacados por Pierre Legrand. Según este comparatista, además del compromiso con la teoría, también debe haber un compromiso con la interdisciplinariedad. [La] 'Ley', dice él, 'no existe en el vacío; es un fenómeno social aunque solo sea porque, como mínimo, opera dentro de la sociedad'. En consecuencia, 'el comparatista debe darse cuenta de que puede aprender mucho de lo que tiene una relevancia directa para su trabajo de la antropología'. (...)Además, agrega, hay muchas cosas que podrían ser de utilidad para el comparatista en el campo de la psicología cognitiva, ya que este 'campo de investigación puede arrojar luz sobre cuestiones tan fundamentales como cuánto puede un abogado francés entender el derecho inglés'" (La traducción nos corresponde). 
condenado durante el cumplimiento de la pena ${ }^{50}$.

Asimismo, entre las fuentes externas utilizadas por el proyecto de 1906, al regular este instituto, se encontraba el Código penal alemán, del 15 de mayo de $1871^{51}$ y el Proyecto de Código Penal Alemán de 1919; que Moreno, expresamente lo reconoce como fuente. Este último texto es muy importante al introducir una innovación central respecto del Código de 1871, y que se reflejó en nuestro artículo 13: nos referimos a que la libertad condicional se otorgaba también a los condenados a la pena perpetua de casa de disciplina (la más grave de las contenidas en el proyecto, luego de la de muerte) que hubiesen cumplido quince años de su pena ${ }^{52}$

Apuntamos estos aspectos porque, creemos, que apartarse de la tradición legislativa local e, incluso, de la tradición en la que abrevan las fuentes externas, constituye una metodología inadecuada. En este caso, observamos que la utilización prudente del Derecho comparado podría haber preservado una regla en relación a la libertad condicional para la prisión perpetua, menos traumática a la que, finalmente, se redactó. Es que, si la tradición legislativa de la norma originaria y de uno de los modelos en las que se inspiró, permitían una solución congruente con nuestros principios constitucionales, su abandono constituye, por lo menos, una imprudencia.

En segundo lugar, aunque también con cierta vinculación con la exigencia anterior, la imitación de determinados modelos requiere prestar particular atención a los lineamientos que caracterizan a las políticas criminales de los diversos Estados que intervienen en este proceso; es decir: ver los contextos político criminales sus semejanzas y sus diferencias - entre el Estado importador y el que elaboró la institución importada. Se trata aquí de evaluar las políticas criminales de cada Estado, al tiempo en que se intenta legislar sobre la base de determinado modelo.

No es lo mismo importar un modelo proveniente de la legislación sueca que de otros países europeos. Y no lo es porque, a diferencia de lo que sucede, por ejemplo, en Francia, la tradición político criminal del país escandinavo se caracteriza, entre otros aspectos, por tratarse de una cultura política basada en el consenso, una alta confianza en las instituciones, una la baja presión social sobre la política, un

50 Moreno, Rodolfo (hijo), El Código Penal y sus antecedentes, H.A. Tommasi, Editor, Bs. As., 1923, p. 78.

51 Cfr. Nota de elevación, en Proyecto de Código Penal (1906), incluido en Zaffaroni, Eugenio Raúl Arnedo, Miguel Alfredo, Digesto de codificación penal argentina, T³ 3- A-Z Editora, Madrid, 1996, p. 268.

52 Al respecto, Caballero, José S., El significado doctrinario y jurisprudencial de la libertad condicional regulada por el Código Penal, Ediciones Lerner, Córdoba, 1964, p. 43. Este autor reconoce al Código alemán y al proyecto considerado por Moreno, como una de las fuentes externas más importantes de esta institución. 
significativo papel reservado a los expertos y una tradicional "despolitización" de la cuestión penal en el pensamiento socialdemócrata ${ }^{53}$; caracteres que no suelen estar presentes, como veremos enseguida, en la política criminal francesa.

Esto tiene relevancia para ponderar la calidad del modelo legislativo que se importa; exigiendo, especialmente, ver si, en los propios contextos de la legislación en que la reforma se inspira, no existieron ya dificultades con la institución que pretende imitarse.

Retornemos, de nuevo, al anteproyecto. La medida de seguridad de seguimiento socio judicial que se introdujo, como lo hemos señalado, proviene del Código penal francés. Ahora bien, esta inclusión se debió, en aquél país, a enmiendas posteriores al Código de 1992 (vigente a partir de 1994); reformas (una de 1998 y otra de 2008) que parten de una idea político criminal que pretende alzaprimar la protección del orden público y el valor seguridad. Al respecto, Pradel ha dicho: "Cabe señalar, sin embargo, que en su preocupación por proteger el orden público, las autoridades (...) tienen la intención de dejar un lugar pequeño para el Estado de Derecho y el principio de un juicio justo"; aclarando que estas orientaciones se manifiestan formalmente a través de una gran profusión de nuevos textos legislativos y expresando que, en el caso particular de Francia, "entre 2007 et 2012, on compte une bonne douzaine de lois pénales d'inspiration répressive"; entre las cuales menciona a la aludida reforma del 25 de febrero de $2008^{54}$.

Estos productos normativos no están exentos de problemas. Buena muestra de ello es que apenas aprobado el texto de 2008, su sanción desató en Francia "una gran polémica, en tanto fue visto por muchos como un 'cambio radical', una 'revolución jurídica' del derecho francés. Ello hizo que sesenta diputados y el mismo número de senadores recurrieran el proyecto ante el Consejo Constitucional" ${ }^{25}$, por considerarlo inconstitucional; específicamente en orden a la retención de seguridad. Y aun cuando, el Consejo, parcialmente la validó, no existen dudas que la opinión jurídica media era plenamente consciente de los problemas que la norma deparaba.

Y aquí cabe una nueva reflexión: ipara que emplear modelos políticos criminales que responden a orientaciones que, en su propio ámbito cultural se observan con

53 Maroto Calatayud, Manuel, "Evaluación y racionalidad político - criminal en los procedimientos legislativos: El ejemplo de Suecia", en Adán Nieto Martín - Marta Muñoz de Morales Romero - José Becerra Muñoz (dirs.), Hacia una evaluación racional de las leyes penales, Ed. Marcial Pons, Madrid, 2016, pp. 181/185.

54 Pradel, Droit..., op. cit., pp. 897/898.

55 Requeso Rodríguez, "Peligrosidad criminal...", op. cit., p. 10. El Consejo se pronunció sobre esta ley a través de su Decisión n 2008-562 DC, 21.2.2008 (J0 26.2.2008 p.3272). 


\section{desconfianza?}

Es más: piénsese que nuestro artículo 52 del Código Penal vigente, que prevé, desde 1921, el instituto de la reclusión por tiempo indeterminado - institución que fue caracterizada por buena parte de la doctrina como una auténtica medida de seguridad - fue declarado inconstitucional por la propia Corte Suprema de Justicia de la Nación en el precedente "Gramajo"56; con lo cual, es obvio también que los climas de la doctrina judicial vernácula en relación a este tipo de medidas post cumplimiento resulta adverso.

Si ya esto es preocupante, aún lo será más si advertimos que no hay ninguna previsión en relación a quien va a controlar esta medida. Si se sigue a la legislación francesa, lo lógico es que tal contralor lo hagan los jueces de ejecución. Y aquí cabe un nuevo interrogante: inuestra judicatura especializada cuenta con los medios humanos y presupuestarios suficientes para esta tarea?

La pregunta no es baladí porque, la eficacia de una institución debe ser evaluada en todas sus dimensiones: de nada sirve imitar instituciones si no sabemos cómo funcionan en el país de origen y sí, en caso que resulte un medio político criminal idóneo imitable, tampoco conocemos si nuestra debilitada justicia de ejecución tiene los medios para efectivizar aquel control.

Ha señalado Pegoraro que, en la praxis, "los trabajos preparatorios de las leyes de varios países evidencian una predilección marcada por el formante normativo. Los legisladores, en otras palabras, aman más (...) citar las soluciones normativas de otros sistemas" ${ }^{57}$. Ahora bien, esta observación paralela y especular de textos normativos, que caracteriza la utilización del Derecho extranjero no es satisfactoria porque, desde la perspectiva del Derecho comparado, raramente permite ver la complejidad que subyace a la fuente utilizada. No hay que olvidar que, detrás de cada ley "existe la cultura jurídica de un país"58. Por eso:

el grado de percepción de la utilidad de estudiar experiencias extranjeras depende también de las políticas de la universidad, de la selección del personal que asiste a los legisladores (...), en definitiva, de factores internos que influyen en la homogeneidad o heterogeneidad del derecho en su conjunto, incluyendo la legislación, la jurisprudencia y la doctrina ${ }^{59}$.

56 Resuelta el 5/9/2006, Fallos 329:3680.

57 Pegoraro, Lucio, Teoría y modelos de la comparación. Ensayos de Derecho Constitucional comparado, Ediciones Olejnik, Santiago de Chile, 2017, p. 107.

58 Ibídem p. 109.

59 Ibídem 


\section{Bibliografía}

Ancel, Marc, Utilità e metodi del diritto comparato. Elementi d'introduzione generale allo studio comparato dei diritti, Edizioni Scientifiche Italiane, Napoli, 2000

Anteproyecto. Código penal de la Nación Argentina. Anteproyecto elaborado por la "Comisión para la Reforma del Código Penal de la Nación", creada por decreto 103/2017. Ed. Eudeba, Bs. As., 2018

Becerra Muñoz, José, La toma de decisiones en la política criminal. Bases para un análisis multidisciplinar, Tirant lo Blanch, Valencia, 2013.

BEck, UlRich, La sociedad del riesgo: hacia una nueva modernidad, Ed. Paidós, Barcelona, 1998.

Beristain, Antonio, "La reforma del Código penal alemán", Anuario de Derecho penal y Ciencias penales, Número 2, Madrid, 1969

Caballero, José S., El significado doctrinario y jurisprudencial de la libertad condicional regulada por el Código Penal, Ediciones Lerner, Córdoba, 1964

Cámara Arroyo, Sergio - Fernández Bermejo, Daniel, La prisión permanente revisable: el ocaso del humanismo penal penitenciario, Thomson Reuters - Aranzadi, Pamplona, 2016

Cesano, José Daniel, "iPenas privativas de la libertad efectivamente perpetuas? (A propósito de un fallo del Superior Tribunal de Justicia de Rio Negro)", Revista de Derecho penal y Procesal penal, Diciembre de 2004, № 4, Ed. LexisNexis, Bs. As.

Cesano, José Daniel, “Consideraciones sobre algunas de las funciones del Derecho comparado", en Gustavo A. Arocena - José Daniel Cesano, Repensando los métodos y desafíos del Derecho penal del siglo XXI. Homenaje al Prof. Dr. Fabián I. Balcarce, Ed. Lerner, Córdoba, 2018

Cesano, José Daniel, Derecho penal comparado. Una aproximación metodológica, Ed. Brujas, Córdoba.

Cesano, José Daniel, La política criminal y la emergencia (Entre el simbolismo y el resurgimiento punitivo), Ed. Mediterránea, Córdoba, 2004.

Cuellar, Gustavo Gabriel, "Anteproyecto de Código Penal 2018. ¿Claves del nuevo código penal de argentina?", p. 5. Disponible en http://www.pensamientopenal. com.ar/system/files/2018/07/doctrina46788.pdfp. Accedido23/03/2019

DuBols LÉA, "Propos introductifs sur la circulation des modèles normatifs: tentative de définitions", en La circulation des modèles normatifs, Sous la direction de PAUL BOURGUES et CAMILLE MONTAGNE, Presses Universitaires de Grenoble, 2017 
Jescheck, Hans - Heinrich, Tratado de Derecho Penal. Parte general, $4^{a}$ Edición, Ed. Comares, Granada, 1993.

López-Medina, Diego, “El nacimiento del Derecho Comparado moderno como espacio geográfico y como disciplina: Instrucciones básicas para su comprensión y uso desde América Latina", International Law: Revista Colombiana de Derecho Internacional, Pontificia Universidad Javeriana, Bogotá, Vol. 13, Núm. 27 (2015). Mancera Cota, Adrián, "Consideraciones durante el proceso comparativo", Boletín Mexicano de Derecho Comparado, №121, Enero de 2008

Maroto Calatayud, Manuel, "Evaluación y racionalidad político - criminal en los procedimientos legislativos: El ejemplo de Suecia", en Adán Nieto Martín Marta Muñoz de Morales Romero - José Becerra Muñoz (dirs.), Hacia una evaluación racional de las leyes penales, Ed. Marcial Pons, Madrid, 2016

Martínez Mora, Gema, Alternativas jurídicas al tratamiento penal de la delincuencia habitual, JB Bosch Editor, Barcelona, 2015

Moreno, Rodolfo (hijo), El Código Penal y sus antecedentes, H.A. Tommasi, Editor, Bs. As., 1923

Ortega Maldonado, Juan Manuel, "El derecho en la sociedad de riesgo", Misión Jurídica. Revista de Derecho y Ciencias Sociales, Vol. 4, № 4, Julio - Diciembre de 2011, Universidad Colegio Mayor de Cundinamarca.

Pastor, Daniel R., "La recodificación penal en marcha. Una iniciativa ideal para la racionalización legislativa", Revista Pensar en Derecho, Coedición Eudeba y Facultad de Derecho de la UBA, Bs. As., 2012.

Pastor, Daniel R., Recodificación penal y principio de reserva de código, Ed. Ad - Hoc, Bs. As., 2005.

Pegoraro, Lucio, Teoría y modelos de la comparación. Ensayos de Derecho Constitucional comparado, Ediciones Olejnik, Santiago de Chile, 2017

Pradel, Jean, Droit Pénal comparé, 4e édition, Dalloz, Paris, 2016

Requejo Rodríguez, Paloma, "Peligrosidad criminal y Constitución", InDret. Revista para el análisis del Derecho, Barcelona, Julio de 2008

Roig Torres, Margarita, La cadena perpetua en el Derecho alemán y británico. La prisión permanente revisable, Ed. lustel, Madrid, 2016

SaÉz Rodríguez, C., "Comentarios acerca del sistema de penas en la proyectada reforma del Código Penal español", InDret. Revista para el análisis del Derecho, Barcelona, № 2, 2013

Samuel, Geoffrey, "All that heaven allows: are transnational codes a 'scientific truth' 
or are they just a form of elegant 'pastiche'?", Methods of Comparative Law, Edited by Pier Giuseppe Monateri, Research Handbooks in Comparative Law, Series Editors: Francesco Parisi and Tom Ginsburg, Published by Edward Elgar Publishing Limited, Cheltenham, UK - Northampton, M.A., USA

Samuel, Geofferey, An Introduction to Comparative Law. Theory and Method, Oxford and Porland, Oregon, 2014

Serra, Francisco, "La actualidad del derecho comparado", en Pedro Aullón Haro (Editor), Metodologías comparatistas y Literatura comparada, Clásicos Dykinson, Madrid, 2012

Somma, Alessandro, Introduzione al Diritto comparato, Editori Laterza, Roma, 2014

Tallon, Denis, "Comparative Law: Expanding Horizons", The Journal of the Society of Public Teachers of Law, vol. X, 1968-1969

Yanzi FerreiRa, Ramón Pedro (Coordinador), Estudios sobre el Anteproyecto de Reforma del Código Penal de la Nación Argentina, Universidad Nacional de Córdoba, Facultad de Derecho y Ciencias Sociales, Secretaría de Posgrado, Córdoba, 2015.

Zaffaroni, Eugenio Raúl - Arnedo, Miguel Alfredo, Digesto de codificación penal argentina, $\mathrm{T}^{\circ}$ 3, A- Z Editora, Madrid, 1996 